\title{
Role of the Vision Van, a mobile ophthalmic outpatient clinic, in the Great East Japan Earthquake
}

This article was published in the following Dove Press journal:

Clinical Ophthalmology

7 April 2014

Number of times this article has been viewed

\section{Kenya Yuki' \\ Toru Nakazawa ${ }^{2}$ \\ Daijiro Kurosaka ${ }^{3}$ \\ Tsunehiko Yoshida ${ }^{4-6}$ \\ Eduardo C Alfonso ${ }^{7}$ \\ Richard K Lee ${ }^{7}$ \\ Shigeru Takano ${ }^{8}$ \\ Kazuo Tsubota'}

'Department of Ophthalmology, Keio University School of Medicine, Tokyo, Japan; 2Department of Ophthalmology, Tohoku University Graduate School of Medicine, Miyagi, Japan; ${ }^{3}$ Department of Ophthalmology, Iwate Medical University, Iwate, Japan; ${ }^{4}$ The House of Representatives of Japan, Tokyo, Japan; ${ }^{5}$ Nagoya University Hospital, Aichi, Japan; ${ }^{6}$ Aichi Medical University Hospital, Aichi, Japan; ${ }^{7}$ Bascom Palmer Eye Institute, University of Miami Miller School of Medicine, Miami, FL, USA; ${ }^{8}$ Japan Ophthalmological Association, Tokyo, Japan
Correspondence: Kazuo Tsubota Department of Ophthalmology, Keio University School of Medicine, Shinanomachi 35, Shinjuku-ku,

Tokyo 160-8582, Japan

Tel +8I 353633869

Fax +8I 353633869

Email tsubota@z3.keio.jp
Purpose: The Great East Japan Earthquake of March 11, 2011 triggered powerful tsunami waves off the northeastern Pacific coast of Japan that destroyed almost all of the built-up areas along the coast. The study reported here examined the role played by the Vision Van, a mobile outpatient ophthalmological clinic, in providing eye care to disaster evacuees.

Methods: This was a retrospective case-series study of 2,070 victims (male: 732, female: 1,338) who visited the Vision Van. The subjects' medical records were examined retrospectively and analyzed in terms of age, sex, and date of visit to the Vision Van. Information regarding each patient's chief complaint, diagnosis, medication(s) prescribed, and eyeglasses and contact lenses provided, was also examined.

Results: The Vision Van was used to conduct medical examinations on 39 days between April 23 and June 29, 2011. The average number of subjects visiting the Vision Van each day was $53 \pm 31$ (range: 7-135), with examinations carried out in Miyagi Prefecture and Iwate Prefecture. The most frequent complaint was a need for eye drops (871/2,070 [42.1\%]). The second and third most frequent complaints, respectively, were the need for contact lenses (294/2,070 [14.2\%]) and eyeglasses $(280 / 2,070$ [13.5\%]). The most frequent ocular disease diagnosis was cataract $(497 / 2,070[24.0 \%])$. Eye drops were prescribed to $74.1 \%$ of the subjects.

Conclusion: Mobile clinics such as the Vision Van provide valuable care, in this case, particularly to individuals who lost or left behind eyeglasses or contact lenses while escaping a natural disaster, and to subjects with chronic eye disease.

Keywords: natural disaster, disaster relief, eye care, mobile medical services

\section{Introduction}

The Great East Japan Earthquake of March 11, 2011 triggered powerful tsunami waves off the northeastern Pacific coast of the Tohoku area of Japan that destroyed almost all of the built-up areas along the coast. ${ }^{1}$ Tragically, 16,140 people perished, nearly 6,000 were injured, and 3,123 were still missing as of February 11, 2012. ${ }^{2}$

The Great East Japan Earthquake had a magnitude of 9.0+ on the Richter scale, making this the largest earthquake in recorded history in Japan, and the fourth largest earthquake ever recorded in the world. ${ }^{3}$ Japan experienced another large earthquake, the Great Hanshin-Awaji Earthquake, on January 17, 1995, which left 6,434 people dead and 43,792 injured. ${ }^{4}$ The major cause of death in the Hanshin-Awaji Earthquake was the earthquake itself, ${ }^{4}$ whereas the larger part of the destruction following the Great East Japan Earthquake was caused by the tsunami. ${ }^{5}$ Many hospitals and outpatient clinics were destroyed by the earthquake and tsunami. Ten hospitals and 84 outpatient clinics were completely destroyed, and 290 hospitals (290/380 [76.3\%]) and 1,176 outpatient 
clinics $(1,176 / 4,036$ [29.1\%]) were partially destroyed in the Iwate, Miyagi, and Fukushima prefectures. ${ }^{6}$ Almost all of these facilities, including most ophthalmological clinics and hospitals, were unable to offer medical services in the wake of the disaster.

Many people with ophthalmological diseases were left untreated because of the disaster, and emergency treatment was largely impossible. Two weeks after the earthquake, we visited northeastern Japan to assess the situation and find ways to help survivors with their ocular needs. At that time, we had limited means of providing assistance because thorough eye exams require bulky instruments. We decided, therefore, to import a mobile eye clinic, the Vision Van, ${ }^{7}$ having heard of its use via the US media when it was used to help people after Hurricane Katrina in $2005 .{ }^{8}$ We contacted the Bascom Palmer Eye Institute to request the use of their Vision Van, and the institute was more than pleased to accommodate us. The Vision Van arrived in Japan on April 14, 2011 and was put into service the following day (Figures 1 and 2). ${ }^{9}$

The object of the study presented here was to report on the role played by the Vision Van in the Great East Japan Earthquake and on the future prospects of ophthalmological care in areas affected by disasters.

\section{Methods}

The procedures used in the study conformed to the tenets of the Declaration of Helsinki and to national (Japanese) and institutional (Keio University School of Medicine) regulations. This retrospective study was approved by the Ethics Committee of Keio University School of Medicine (\#2012409). While the Vision Van was in

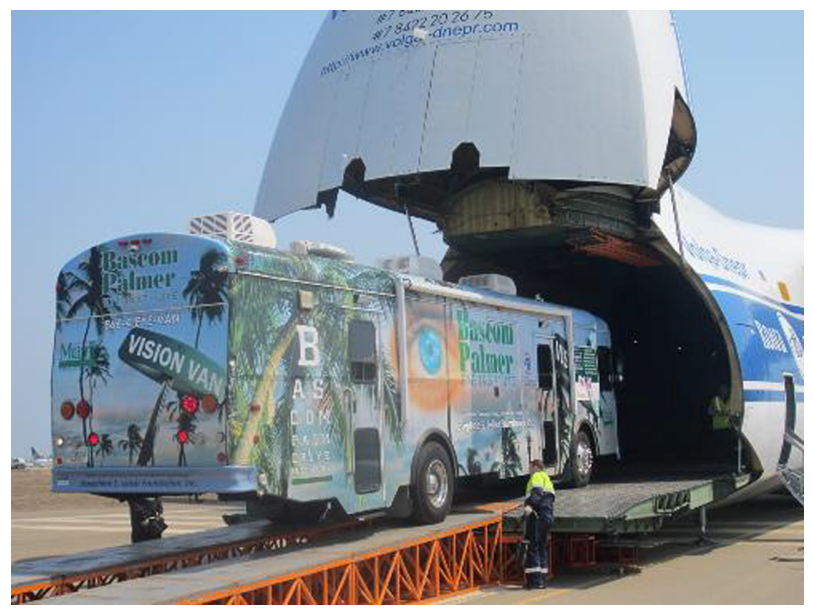

Figure I The Vision Van being unloaded from the cargo airplane that transported it to Sendai.

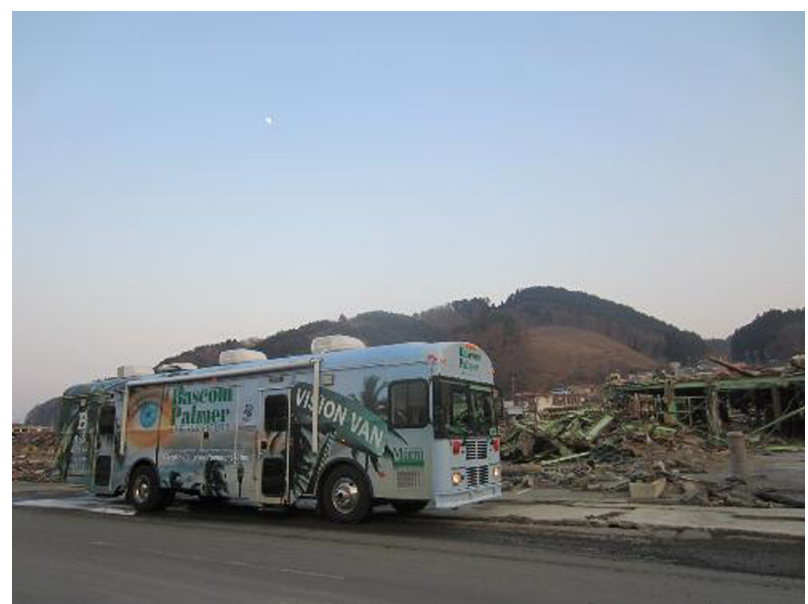

Figure 2 The Vision Van on the first day of its rescue mission.

service (April 14 to June 29, 2011), examinations were conducted according to the subjects' needs. The Vision Van is a 40-foot-long, custom-designed, custom-built bus equipped with a slit lamp (BP 900, Haag-Streit Diagnostics, Koenig, Switzerland), binocular indirect funduscope (Keeler Ophthalmic Instruments Inc., Broomall, PA, USA), tonometer (CT-80 noncontact tonometer, Topcon Corporation, Tokyo, Japan), and autorefractor (ARK-1A, Nidek Co, Ltd, Aichi, Japan), as well as a satellite Internet connection and ample storage space. This made it possible to conduct refraction testing, visual acuity and intraocular pressure (IOP) measurements, slit-lamp biomicroscopy, and un-dilated or dilated indirect funduscopy (Figure 3). For this study, the medical records of subjects who visited the Vision Van were examined retrospectively in terms of age, sex, reason for visiting the Vision Van, date of visit, diagnosis, and medication(s) prescribed.

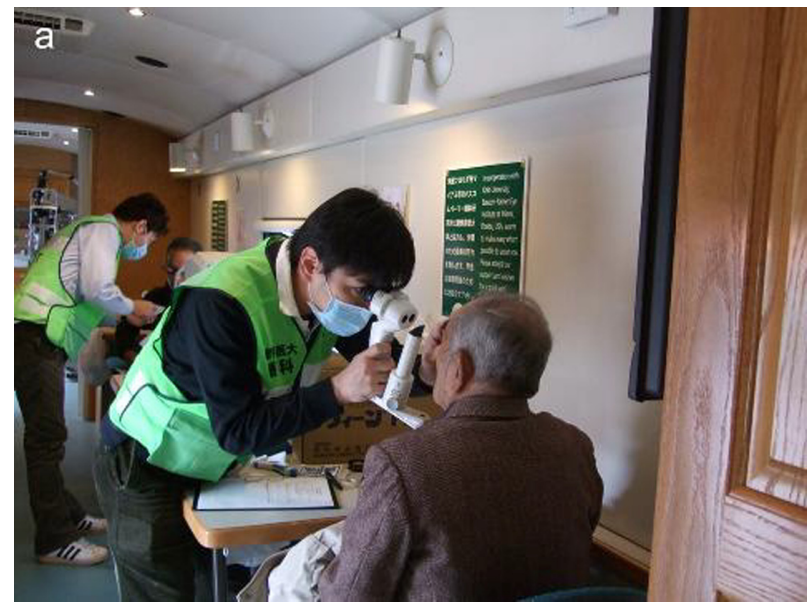

Figure 3 Inside view of the Vision Van. Doctors use hand-held slit-lamp microscopes to examine evacuee subjects. 


\section{Results}

Medical examinations were carried out in the Vision Van on 39 days between April and June 2011 in Ishinomaki City, Higashimatsushima City, Onagawa Town, Kesennuma City, and Ogatsu-cho in Miyagi Prefecture, and Rikuzentakata City, Otsuchi-cho, Rikuzentakata City, and Yamada Town in Iwate Prefecture. No examinations were performed in Fukushima Prefecture. The Vision Van was visited by 2,070 subjects (male: 732 , female: 1,338 ) with an average age of $61.4 \pm 20.2$ years (range $0-99$ years).

The number of subjects who visited the Vision Van each day is shown in Figure 4, and the number who sought treatment at each location is shown in Table 1. An average of $53 \pm 31$ (range: 7-135) subjects visited the Vision Van per day.

The types and rates of chief complaints are shown in Figure 5. The most frequent complaint was the need for eye drops (871/2,070 [42.1\%]). Many of the subjects lost their daily-use eye drops secondary to the disaster. The second and third most frequent complaints, respectively, were the need for contact lenses (294/2,070 [14.2\%]) and for eyeglasses (280/2,070 [13.5\%]). Many myopic subjects had lost their contact lenses and eyeglasses, and visited the Vision Van to obtain replacement corrective eyewear. Of the 490 people (26.3\%) over 50 years old who visited the Vision Van in Miyagi Prefecture, 129 requested reading glasses.

Eye drops were prescribed for $74.1 \%(1,534 / 2,070)$ of the subjects; the types prescribed are shown in Figure 6. Eye drops for dry eye were the most commonly prescribed $(585 / 2,070$ [28.3\%]), followed by drops for cataract (453/2,070 [21.9\%]), and for glaucoma (245/2,070 [11.9\%]). Nonsteroidal anti-inflammatory eye drops and anti-allergy eye drops were also prescribed in $243(11.7 \%)$ and $168(8.2 \%)$ cases, respectively.
The types and rates of diagnosis are shown in Figure 7. The most frequent diagnosis was cataract (497/2,070 [24.0\%]). Many of the cataract subjects were using anti-cataract eye drops (pirenoxine [1,5-Dioxo- $4 H$-pyrido[3,2- $a]$ phenoxazine3-carboxylic acid] - Kary Uni ${ }^{\circledR}$ ophthalmic suspension $0.005 \%$, Santen Pharmaceutical Co, Ltd, Osaka, Japan), ${ }^{10}$ and visited the Vision Van for supplies. The second most frequent diagnosis was glaucoma (241/2,070 [11.6\%]). Almost all of the subjects with glaucoma visited the Vision Van because they did not have anti-glaucoma medication. The third most frequent diagnosis was myopia (201/2,070 [9.7\%]).

The Vision Van also cared for subjects with eye-threatening emergency conditions. These included two cases of retinal-flap tear requiring laser photocoagulation, one case of steroid-induced IOP elevation, one case of an iron foreign body in the cornea, and six cases of bacterial corneal ulcers. These subjects were all treated immediately.

\section{Discussion}

Herein, we present an overview of the role played by the Vision Van in disaster relief operations following the Great Japan East Earthquake of March 2011. During the nearly 3 months of the Vision Van's rotation in Iwate and Miyagi prefectures, 2,070 subjects were seen, 1,534 of whom were given medications.

After the disaster, we thought that the immediate need would be for treatment of emergency conditions such as blunt ocular trauma, corneal perforation or abrasions, and ocular surface burns. However, the evacuees' major needs centered around pre-existing chronic conditions, including cataracts, allergic conjunctivitis, glaucoma, dry eye, diabetic retinopathy, and retinal disease. Of the subjects treated in the Vision Van, 99\% required medical care for chronic conditions. The nearby hospitals and ophthalmological outpatient clinics had

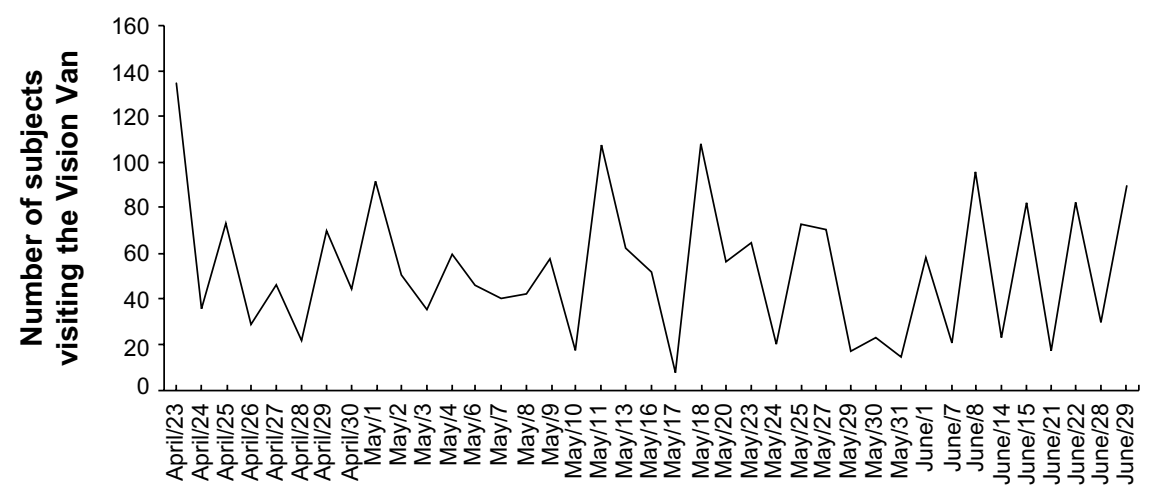

Dates when the Vision Van was used

Figure 4 The number of subjects seen by the Vision Van during its 39-day rescue mission in 2011. 
Table I The number of subjects who visited the Vision Van from each location

\begin{tabular}{|c|c|c|c|c|c|c|c|c|c|}
\hline & \multicolumn{4}{|c|}{ Iwate prefecture } & \multicolumn{4}{|c|}{ Miyagi prefecture } & \multirow[t]{2}{*}{ Total } \\
\hline & Yamada & Otsuchi & Takata & Onagawa & Ishinomaki & Ogatsu & Higashimatsushima & Kesennuma & \\
\hline Total days & 10 & 10 & 6 & 5 & 1 & 1 & 4 & 2 & 39 \\
\hline $\begin{array}{l}\text { Total number } \\
\text { of subjects }\end{array}$ & 808 & 410 & 121 & 304 & 135 & 92 & 116 & 84 & 2,070 \\
\hline Average per day & 80.8 & 41.0 & 20.2 & 60.8 & - & - & 29.0 & 42.0 & \\
\hline Standard deviation & 21.1 & 21.3 & 10.3 & 10.2 & - & - & 11.5 & 2.8 & \\
\hline
\end{tabular}

been partially or totally destroyed in the disaster and were unable to function for at least several months. Transportation systems were also destroyed, so many victims were unable to reach those ophthalmologists still able to provide services. Therefore, many subjects with glaucoma, cataracts, or dry eye were unable to obtain necessary medications and treatment. The lack of daily anti-glaucoma eye drops resulted in increased IOP in some glaucoma subjects, which is a significant risk factor in the progression of glaucomatous optic neuropathy. ${ }^{11}$

Some elderly victims who had diseases such as glaucoma but who were not troubled by symptoms tended to quit visiting doctors in the aftermath of the tsunami. Therefore, we used posters and radio advertising to make this population aware of the activity of the Vision Van, the necessity for examination by ophthalmologists, and to encourage them to attend the Vision Van for treatment. One of the lessons learned from this disaster is the importance of providing care as quickly as possible to those with chronic conditions.

More than 1,000 evacuees were relocated to evacuation centers. We had to find ways to inform this large evacuee population at short notice that the Vision Van would be going to an evacuation center. The distinct appearance of the bus, painted with tropical Florida palm trees, a large eye, and a Snellen chart, was easily associated with ophthalmic care. The Vision Van's visibility drew people's attention to its offer of ophthalmic care at evacuation centers.

The main cause of death and injury in this disaster was the tsunami, ${ }^{5}$ whereas in the 1995 Hanshin-Awaji Earthquake, the major cause of trauma was buildings collapsing onto

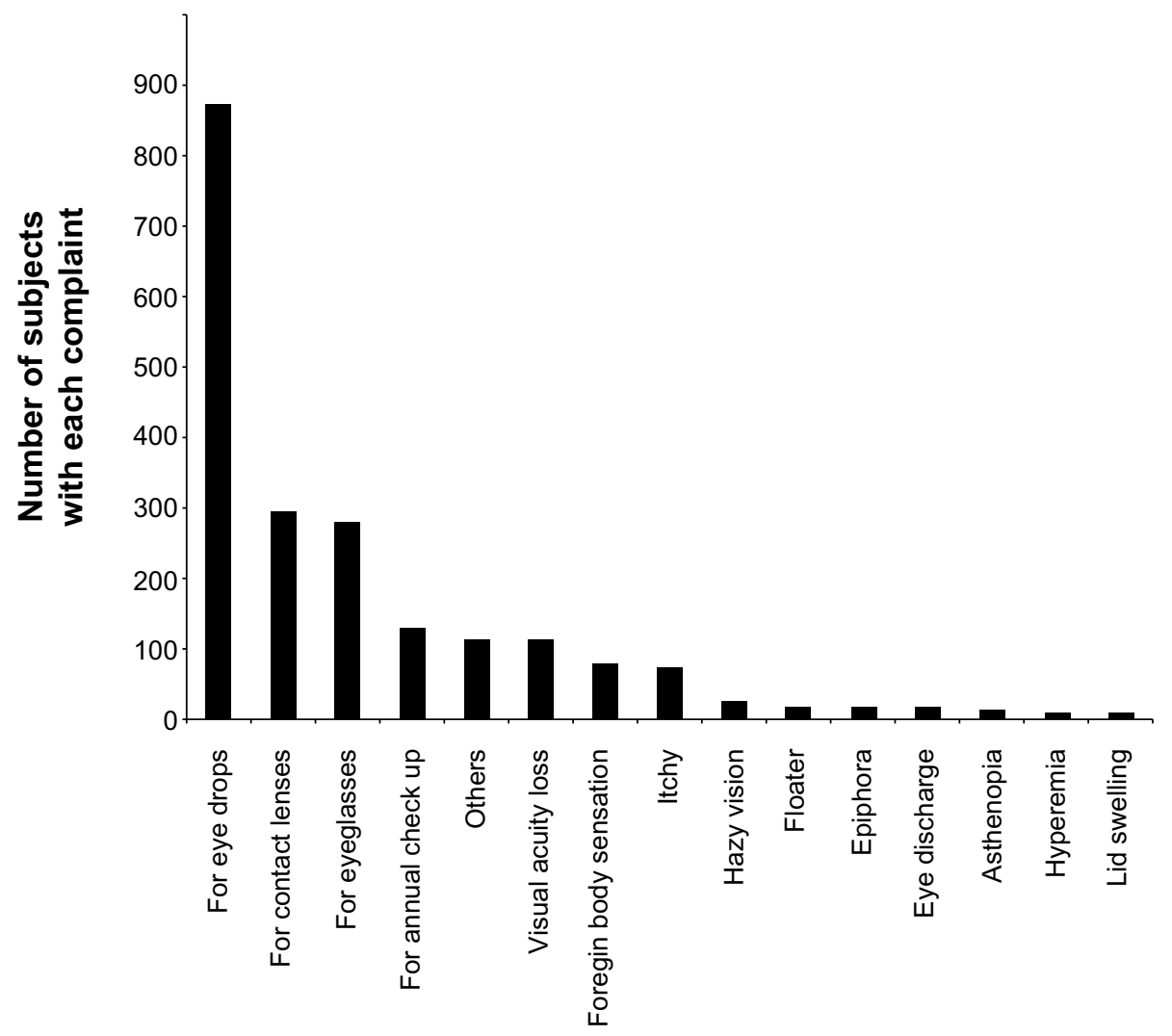

Figure $\mathbf{5}$ The number of subjects presenting with each complaint at the Vision Van. 


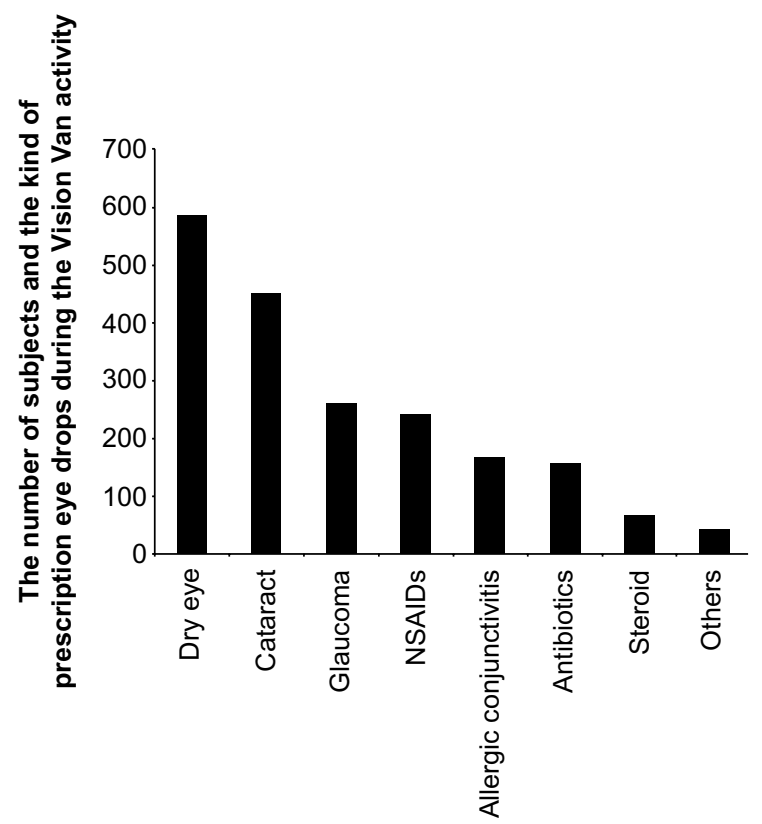

Figure 6 Prescriptions dispensed per condition during the Vision Van's activity. Abbreviation: NSAIDs, nonsteroidal anti-inflammatory drugs.

people due to the earthquake itself. In the Great East Japan Earthquake, the tsunami washed away houses and buildings together with their contents, which included eyeglasses, contact lenses, contact-lens preservatives, and eye medications. It is easy to infer that people could not gather and take care

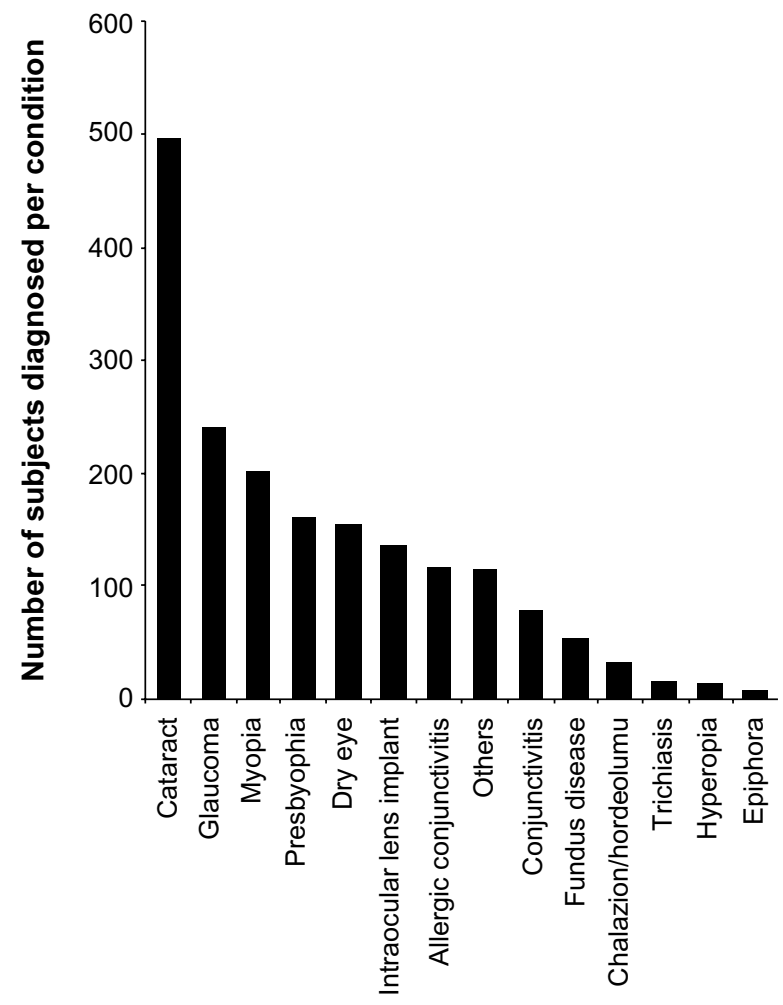

Figure 7 Diagnoses (number of people) made in the Vision Van. of these items when their very lives were threatened by the tsunami and shock waves.

After evacuation, reduced visual acuity meant a reduced quality of life for those in evacuation centers who had lost their glasses. Lack of refractive error correction is associated with a significant decrease in the quality of life related to vision. ${ }^{12}$ Within the evacuation centers, the only sources of information and entertainment were often television and newspapers. In Miyagi Prefecture, 26\% of those aged 50 years or older who visited the Vision Van needed reading glasses. Since many elderly people cannot read or watch television without glasses, a lack of glasses may result in decreased mental health, and can even be life-threatening if it prevents an individual from obtaining adequate information about his or her surroundings.

In Japan, the prevalence of myopia (spherical equivalent [SE] less than -0.5 diopters [D]) and high myopia (SE less than $-5.0 \mathrm{D}$ ) is reported to be $41.8 \%$ and $8.2 \%$, respectively. ${ }^{13}$ It should be noted that of the 731 people who visited the van in Miyagi Prefecture, 133 (18.2\%) needed eyeglasses for myopia correction. Uncorrected visual acuity in elderly people with myopia can result in reduced postural stability, ${ }^{14,15}$ a decline in activities of daily living, ${ }^{16}$ and an increased fear of falls. ${ }^{17}$ Following the disaster, several eyeglass and contact-lens manufacturers provided their products free of charge, which was of untold benefit to many of the evacuees. While the need for food, drink, and daily supplies following disasters is obvious, it should not be forgotten that eyeglasses are almost as essential in improving the quality of life of evacuees and preventing injury due to the unseen dangers inherent in unfamiliar surroundings, such as in an evacuation center.

The loss of contact-lens preservatives was also a serious problem, because many evacuees were forced to use their contact lenses without proper care. Six $(6 / 2,037$ [0.4\%]) of the visitors to the Vision Van were treated for corneal ulcers. Whether these ulcers were caused by contact lenses is unclear, but it is likely that the inappropriate use of contact lenses was responsible for some cases of corneal ulcers in this disaster. Sufficient stocks of contact lenses and preservatives should be maintained in preparation for future disasters.

In this disaster, the Vision Van began its activity 1 month after the Great East Japan Earthquake. Some individuals who used 2-week contact lenses had to use expired contact lenses. Wearing expired contact lenses is a known risk factor for contact-lens-induced diseases such as bacterial corneal ulcers. ${ }^{18}$ Thus, it is important to start emergency 
ophthalmic services as soon as possible, in part to avoid the use of expired contact lenses. Most companies in Japan, including hospitals, try to keep stock levels as low as possible for the sake of efficiency and to reduce storage costs. However, this policy causes obvious problems when transportation systems cease to function. Since earthquakes and other disasters occur regularly in Japan, hospitals should avoid keeping such low stocks of medical supplies that they cannot mount a reasonable response to acute needs in the wake of a disaster.

Many members of the Japanese Self-Defense Forces who were deployed for disaster relief also lost eyeglasses and contact lenses. For such people, a problem with glasses or contact lenses is more than an inconvenience; they cannot work in critical situations with uncorrected myopia.

More earthquakes and other natural disasters are inevitable in the future, and proper facilities to provide emergency medical care should be prepared in advance. Mobile clinics such as the Vision Van provide valuable care to individuals displaced in the event of a disaster, and can also be used in nonemergency conditions to provide services to those living in remote locations.

\section{Acknowledgments}

We thank the University of Miami Miller School of Medicine and its Bascom Palmer Eye Institute, Volga-Dnepr Airlines, the Japanese Ophthalmological Society, the Japan Ophthalmologists' Association, the Iwate Ophthalmologists' Association, the Miyagi Ophthalmologists' Association, Medi Produce, Inc., (Tokyo, Japan) and the Japanese Government for their support of the Mission Vision Van Project. We are also deeply indebted to all the health care professionals who volunteered their time and skills to care for subjects displaced by the tsunami.

Funding/Support was received from the Mission Vision Van Committee, Tokyo, Japan, which also participated in data collection for this paper.

\section{Disclosure}

The authors declare no conflicts of interest in this work.

\section{References}

1. Japan: health after the earthquake. Lancet. 2011;377(9970):968.

2. Fire and Disaster Management Agency. Great East Japan Earthquake in 2011 (Report number 144). Available from: http://www.fdma.go.jp/bn/ higaihou/pdf/jishin/144.pdf. Accessed December 6, 2013. Japanese.

3. US Geological Survey (USGS). Magnitude 8 and greater earthquakes since 1900 [web page on the Internet]. Reston, VA: USGS; nd [updated April 14, 2011]. Available from: http://earthquake.usgs. gov/earthquakes/eqarchives/year/mag8/magnitude8_1900_date.php. Accessed December 6, 2013.

4. Tanaka K. The Kobe earthquake: the system response. A disaster report from Japan. Eur J Emerg Med. 1996;3(4):263-269.

5. Normile D. Japan disaster. Waves of destruction. Science. 2011; 331(6023): 1376.

6. Ministry of Health, Labour and Welfare Extent of damage of hospitals and clinics in Great East Japan Earthquake. Available from: http://www. mhlw.go.jp/stf/shingi/2r9852000001yxlj-att/2r9852000001yy9a.pdf. Accessed December 6, 2013. Japanese.

7. Tsubota K, Yoshida T, Kurosaka D, Lee RK, Alfonso EC, Nakazawa T. Miami to Japan eye-care rescue mission: Vision Van helps with relief efforts. Am J Ophthalmol. 2011;152(5):886-887.

8. Dalton M. Bascom Palmer's Vision Van offered services to battered Louisiana. Ocular Surgury News. October 15, 2005. Available from: http://www.osnsupersite.com/view.aspx?rid=12678. Accessed January 7, 2014.

9. Oshima CR, Yuki K, Uchida A, et al. The Vision Van, a mobile eye clinic, aids relief efforts in tsunami-stricken areas. Keio J Med. 2012;61(1):10-14.

10. Hu CC, Liao JH, Hsu KY, et al. Role of pirenoxine in the effects of catalin on in vitro ultraviolet-induced lens protein turbidity and seleniteinduced cataractogenesis in vivo. Mol Vis. 2011;17:1862-1870.

11. Coleman AL, Miglior S. Risk factors for glaucoma onset and progression. Surv Ophthalmol. 2008;53 Suppl 1:S3-S10.

12. McClure TM, Choi D, Wooten K, Nield C, Becker TM, Mansberger SL. The impact of eyeglasses on vision-related quality of life in American Indian/Alaska Natives. Am J Ophthalmol. 2011;151(1):175-182.

13. Sawada A, Tomidokoro A, Araie M, Iwase A, Yamamoto T; Tajimi Study Group. Refractive errors in an elderly Japanese population: the Tajimi study. Ophthalmology. 2008;115(2):363-370.

14. Anand V, Buckley JG, Scally A, Elliott DB. Postural stability changes in the elderly with cataract simulation and refractive blur. Invest Ophthalmol Vis Sci. 2003;44(11):4670-4675.

15. Anand V, Buckley JG, Scally A, Elliott DB. Postural stability in the elderly during sensory perturbations and dual tasking: the influence of refractive blur. Invest Ophthalmol Vis Sci. 2003;44(7):2885-2891.

16. Lamoureux EL, Saw SM, Thumboo J, et al. The impact of corrected and uncorrected refractive error on visual functioning: the Singapore Malay Eye Study. Invest Ophthalmol Vis Sci. 2009;50(6):2614-2620.

17. Klein BE, Moss SE, Klein R, Lee KE, Cruickshanks KJ. Associations of visual function with physical outcomes and limitations 5 years later in an older population: the Beaver Dam eye study. Ophthalmology. 2003;110(4):644-650.

18. Stapleton F, Edwards K, Keay L, et al. Risk factors for moderate and severe microbial keratitis in daily wear contact lens users. Ophthalmology. 2012;119(8):1516-1521.
Clinical Ophthalmology

\section{Publish your work in this journal}

Clinical Ophthalmology is an international, peer-reviewed journal covering all subspecialties within ophthalmology. Key topics include: Optometry; Visual science; Pharmacology and drug therapy in eye diseases; Basic Sciences; Primary and Secondary eye care; Patient Safety and Quality of Care Improvements. This journal is indexed on Submit your manuscript here: http://www.dovepress.com/clinical-ophthalmology-journal

\section{Dovepress}

PubMed Central and CAS, and is the official journal of The Society of Clinical Ophthalmology (SCO). The manuscript management system is completely online and includes a very quick and fair peer-review system, which is all easy to use. Visit http://www.dovepress.com/ testimonials.php to read real quotes from published authors. 